\title{
ENTREVISTA COM CÉLIA A. F. CARTA WINTER E NANCY G. DE OLIVEIRA CARNEIRO SOBRE O LIVRO: DIFERENTES OLHARES SOBRE FENÔMENOS PSI: UMA CONTRIBUIÇÃO PARA A FORMAÇÃO PROFISSIONAL ${ }^{1}$
}

\author{
Célia A. F. Carta Winter and Nancy G. de Oliveira Carneiro in \\ Interview about the Book. "Diferent Points of View about the Psy \\ Phenomenon: a Contribution to the Professional Formation"
}

Andréia Fernanda Silveira é Psicóloga, formada pela PUCPR, Mestre em Psicologia pela UFSC e Doutora em Psicologia Social pela PUCSP. Pesquisadora Sênior do Instituto Ethos de Pesquisa Aplicada, é também organizadora do Livro "Cidadania e Participação Social", publicado pela ABRAPSOSUL. Célia Aparecida Ferreira Carta Winter é Psicóloga, formada pela PUCPR, Especialista em Filosofia da Educação pela PUCPR, Mestre em Psicanálise pela UTP, Mestre em Filosofia pela PUCPR. Membro aderente da Escola Brasileira de Psicanálise, Coordenadora do Curso de Especialização em Saúde Mental, Psicopatologia e Psicanálise da PUCPR, membro do corpo docente do Curso de Psicologia da PUCPR e do Curso de Direito da FACINTER, onde ministra psicologia jurídica. Autora do livro "Confissão e Cura: uma interlocução entre Foucault e a psicanálise freudiana-lacaniana", publicado pela editora Juruá. Nancy Greca de Oliveira Carneiro é Psicóloga, formada pela PUCPR, Especialista em Psicologia Clínica pela UTP e em Terapia Geral dos Signos pela UFPR, Mestre em Antropologia Social pela UFPR. É Psicanalista, Coordenadora do Curso de Especialização em Saúde Mental, Psicologia e Psicanálise da PUCPR, membro do corpo docente do Curso de Psicologia da PUCPR.

Pergunta: Como surgiu a idéia de escrever este livro?

Resposta/Célia: Do desejo de fazer valer a aposta que tem norteado o curso de Especialização em Saúde Mental/Psicopatologia e Psicanálise e que é, antes de qualquer coisa, um deslocamento do saber, do pensamento positivista/cartesiano, assentado no projeto moderno da constituição da subjetividade sob a marca exclusiva da Razão, para a idéia de uma não existência do saber "a priori" ou da verdade a ser transmitida, o que resulta no desconforto de sair do lugar da explicação para o lugar do aprendiz.

SILVEIRA, Andréa Fernanda; WINTER, Célia Aparecida Ferreira Carta; CARNEIRO, Nancy Greca de Oliveira (Org). (2005). Diferentes olhares sobre fenômenos psi: Uma contribuição para a formação profissional. (Coleção Psicologia Saúde Mental, 1). Curitiba: Champagnat.

2 Psicóloga e Professora do Curso de Psicologia da PUCPR. e-mail: renate.vicente@pucpr.br 
Resposta/Nancy: No sentido de promover a reflexão e o debate sobre os fundamentos epistemológicos, metodológicos e éticos de temas ligados à área de Saúde Mental, um grupo de professores do Departamento de Psicologia da PUCPR iniciou, no início do ano 2000, um percurso no campo da Pós-Graduação lato sensu com um Curso de Especialização em Saúde Mental, Psicopatologia e Psicanálise. O Curso se constituiu em torno de grandes campos, a saber: Saúde Mental, Psicopatologia e Psicanálise. No ano de 2004, apresentou o Curso de Psicologia Clínica Abordagem Psicanalítica. Ambos os programas de orientação psicanalítica interrogam acerca da Psicanálise nestes nossos tempos.

O curso se orienta, portanto, pelas contribuições que a Psicanálise pode oferecer no campo da Psicanálise Aplicada às Instituições. Busca introduzir o dispositivo psicanalítico como estratégia de intervenção clínica, nas instituições em geral e nas instituições de saúde mental em particular, e supõe, ao considerar no lugar de um sujeito tomado como objeto pelo discurso biopsicossocial, a inclusão do sujeito da palavra e com ela a necessária modificação no trabalho clínico.

A substituição do modelo hospitalocêntrico pelo modelo de atenção psicossocial impõe novos paradigmas, tais como a possibilidade de pacientes psiquiátricos graves e em crise serem tratados na comunidade. Esta nova forma de atenção, que tenha como eixo a inserção social, deve operar com: diferentes modos de conceber a loucura; diferentes tratamentos; considerar as variáveis existentes no espaço social que interferem diretamente na evolução dos transtornos mentais. Evidencia-se a necessidade de se conduzir à reabilitação em dois sentidos: um sentido que poderíamos nomear como de reabilitação social, que assimila o sujeito do ponto de vista ocupacional ou mesmo de consumidor, e um segundo sentido, que chamaremos de reabilitação jurídica, em que o sujeito se reconstrói ou se constrói como um sujeito de direito, direito pleno à cidadania e a seu exercício. Ora, o projeto psicossocial não pode significar a ausência de uma clínica que considere as diferentes subjetividades.

Resposta/Célia: Todos os movimentos ligados à luta antimanicomial, à reforma psiquiátrica e à inserção social baseiam-se nesta proposta - acolher a diferença-mas, na prática, apesar de equipes multidisciplinares manifestarem este desejo, o que vigora é a crença e a postura que cada um tem um saber-fazer com o "desviante". Sair da posição de especialista é abrir-se para uma construção conjunta de novos sentidos e ações: "é querer o que se deseja".

Resposta/Nancy: Por considerarmos que uma reabilitação sem a clínica implica na prevalência da norma e na normalização dos sujeitos, com sua conseqüente anulação da diferença, a anulação da singularidade dos sujeitos, constituímos o Curso sustentado na Ética da Psicanálise.

Pergunta: Do que trata o livro?

Resposta/Célia: O livro trata dos "Diferentes Olhares sobro o Fenômeno Psi" e sua proposta é a de não fixar um pensamento modelar, cuja tendência é a valorização do "todos iguais", das configurações igualitárias e das generalizações, em detrimento das diferenças. "Diferentes olhares" é um convite para abertura à dimensão ética, no sentido psicanalítico, no qual a diferença possa não ser negada ou avaliada como um desvio à norma. Psicologia?

Pergunta: Qual a contribuição para a

Resposta/Nancy: No campo da Saúde Mental, o livro se insere na dupla perspectiva de responder às necessidades e demandas emergentes da realidade da saúde mental em nosso Estado e à formação de profissionais capacitados para a interpretação, ação, pesquisa e intervenção que o processo de Reforma Psiquiátrica em curso no país exige.

Resposta/Célia: A psicologia é um campo fecundo neste debate e tem por "dever de ofício" questionar para além das diretrizes indicadas pela reforma, certos impasses que se evidenciam em sua efetivação.

Recebido em: 20/05/2007

Received in: 05/20/2007

Aprovado em: 10/06/2007

Approved in: 06/10/2007 